\title{
TWO HUNDRED AND ONE CASES OF INTRACRANIAL TUBERCULOMA TREATED SURGICALLY
}

\author{
BY \\ C. ARSENI \\ From the Neurosurgical Clinic, Bucharest, Rumania
}

Of 38,510 patients admitted to the Neurosurgical Clinic of Bucharest during the 23-year period 1935-57, 2,757 were operated upon for expanding intracranial lesions. These included 201 cases of tuberculoma in patients of ages varying from 3 months to 68 years, the highest incidence being recorded under 30 years of age, particularly in the age group below 20 (Table I). The relative frequency of tuberculoma in children is due to the fact that tuberculous infection is relatively commoner during childhood, usually being followed by tuberculoma within a short interval (one month to one year). In patients under 20 , the tuberculoma is usually infratentorial, while after the age of 20 it is equally frequent in the infra- and in the supra-tentorial areas.

TABLE I

FREQUENCY OF INTRACRANIAL TUBERCULOMA IN RELATION TO AGE

\begin{tabular}{|c|c|c|c|c|c|c|c|}
\hline $\begin{array}{l}\text { Age of patients } \\
\text { in years } \\
\text { Number }\end{array}$ & $\begin{array}{c}0-10 \\
15\end{array}$ & $\begin{array}{c}10-15 \\
49\end{array}$ & $\begin{array}{c}15-20 \\
42\end{array}$ & $\begin{array}{c}20-30 \\
71\end{array}$ & $\begin{array}{c}30-40 \\
10\end{array}$ & $\begin{array}{c}40-50 \\
11\end{array}$ & $\begin{array}{c}\text { Over } \\
50 \\
3\end{array}$ \\
\hline
\end{tabular}

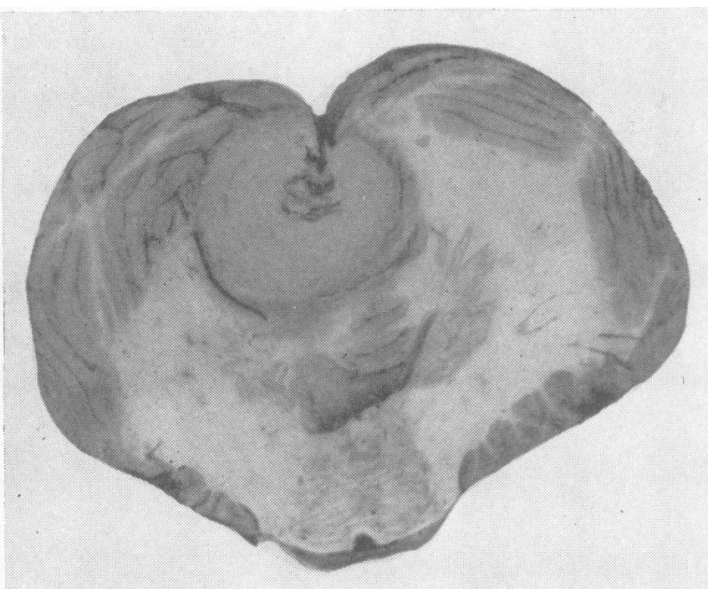

Fig. 1.-Horizontal section of the cerebellum. The tuberculoma is clearly outlined.
Supratentorial tuberculomas are observed more often in men than in women, in a proportion of 3 to 1 , whereas those localized below the tentorium are found equally in men and in women.

We met with 32 cases of multiple tuberculoma, in 12 of which the lesions were confined to the cerebellum and in four to the brain-stem; the other 16 had both supra- and infra-tentorial tuberculomas.

The most frequently recorded site (Fig. 1) was in the posterior fossa $(67 \%) ; 62.5 \%$ had a median or paramedian localization within the cerebellum, and $4.5 \%$ in the brain-stem. In the cerebrum the most frequent sites were the frontal and parietal lobes, and far less often the temporal lobes, the centrum ovale, the basal ganglia, and only exceptionally, the occipital lobe. The incidence was the same in both hemispheres (Table II).

TABLE II

DISTRIBUTION OF SINGLE AND MULTIPLE TUBERCULOMAS

\begin{tabular}{|c|c|c|c|}
\hline \multirow{2}{*}{ Number of Tuberculomas } & \multicolumn{3}{|c|}{ Site } \\
\hline & Cerebrum & Cerebellum & Brain-stem \\
\hline $\begin{array}{l}169 \text { single tuberculomas } \\
32 \text { multiple tuberculomas }\end{array}$ & $51\left\{\begin{array}{l}\text { R.26 } \\
\text { L.25 } \\
16\end{array}\right.$ & $113\left\{\begin{array}{l}\text { R.53 } \\
\text { L.60 } \\
12\end{array}\right.$ & $\begin{array}{l}5 \\
4\end{array}$ \\
\hline
\end{tabular}

Twenty per cent of the total number of tuberculomas were small (less than $15 \mathrm{~g}$.) and these were usually multiple (two to six); $50 \%$ of all tuberculomas were of medium size (15 to $20 \mathrm{~g}$.), $27 \%$ large (over $20 \mathrm{~g}$.), and $3 \%$ were of exceptional size (60 to $100 \mathrm{~g}$.). Clinical symptoms were not proportional to the size of the tuberculoma.

Sixty-six per cent were caseous tuberculomas, $28 \%$ were sclerosing, $5.5 \%$ were calcified, and one only was described as an abscess. In two-thirds of the cases we noted central necrosis (Fig. 2); in $45 \%$ the tuberculoma was in contact with the meninges of the ventricles.

The clinical symptoms were precipitated by infectious diseases, such as measles, whoopingcough, and influenza, in $13 \%$ of the cases; by 


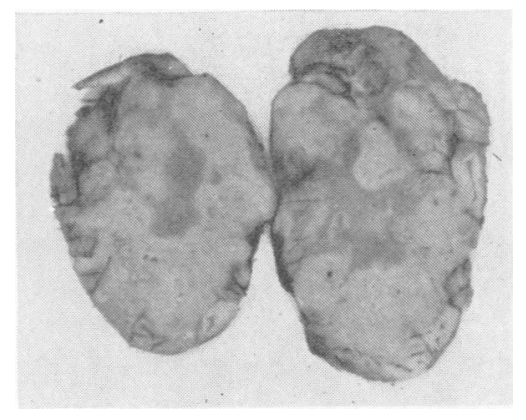

FIG. 2.-Section through a tuberculoma. Necroses are visible in the central area.

cranio-cerebral injuries in $8 \%$; and by pregnancy, which is liable to aggravate the evolution of tuberculomas in the same way as in cerebral tumours, in $1 \%$.

There was a history of tuberculous infection in $52 \%$ of our patients. Pulmonary tuberculosis was noted in the history of $43 \%$ of the cases, either in its progressive form $(21 \%)$ or in the form of residual scars $(22 \%)$. Chronic extrapulmonary tuberculous lesions were found in $9 \%$ of the cases, viz., skin tuberculosis (two cases); lymph node tuberculosis (six cases); ophthalmic tuberculosis (one case); laryngitis (one case); osteo-articular tuberculosis (one case); Pott's disease (three cases); cold abscess (one case); pleuro-peritoneal tuberculosis (one case); and epididymitis (two cases).

In one case the tuberculoma appeared simultaneously with the primary infection. In $21 \%$ of the patients with active tuberculous lesions the tuberculoma developed at a late stage. It appeared most frequently $(31 \%)$ several months or years after the start of the chronic disease. The tuberculoma was apparently primary in $43 \%$ of cases, but not infrequently $(29 \%)$ a source of infection could be traced either within the family or in other contacts. Tuberculoma appeared simultaneously with meningitis in only $3 \%$.

In $20 \%$ of our cases, the disease had been progressing for less than three months before the patient was admitted to the clinic; in $30 \%$ it had lasted for less than one year; in $45 \%$ it had started one to two years before admission; and in $5 \%$ between two and three years. In $15 \%$ of the cases the general health had been impaired, in $53 \%$ the degree of ill-health was moderately severe, and in $32 \%$ the general condition was good.

The clinical features of intracranial tuberculoma were found to be related to the site of the lesion and were therefore of the same order as in any other expanding intracranial process. Tuberculomas of the cerebral hemispheres induced a local clinical syndrome in $68 \%$ of the cases; in $72 \%$ of our patients there were symptoms of intracranial hypertension; $85 \%$ of our cases had generalized or focal epileptic fits. In all cases of cerebellar tuberculoma, intracranial hypertension was present, and in $71 \%$ of them it was associated with a syndrome of localization (a cerebellar syndrome in $62 \%$, and a syndrome of the ponto-cerebellar angle in $9 \%$ ). The ponto-cerebellar angle syndrome was associated with a secondary cystic arachnoiditis of the ponto-cerebellar angle, and it was induced by tuberculomas situated in the external third of the cerebellum. In $12 \%$ of these cases we noted infratentorial tonic fits.

Tuberculomas situated in the brain-stem always induced local signs and symptoms, whereas raised intracranial tension was delayed or inapparent in $33 \%$ (Table III).

TABLE III

CLINICAL FEATURES OF TUBERCULOMAS OF THE CENTRAL NERVOUS SYSTEM

\begin{tabular}{l|c|c|c}
\hline Symptoms & $\begin{array}{c}\text { Brain } \\
\text { (67 cases) }\end{array}$ & $\begin{array}{c}\text { Cerebellum } \\
\text { (125 cases) }\end{array}$ & $\begin{array}{c}\text { Brain-stem } \\
\text { (9 cases) }\end{array}$ \\
\cline { 1 - 2 } $\begin{array}{c}\text { Signs of intracranial hyper- } \\
\text { tension }\end{array}$ & $72 \%$ & $100 \%$ & $33 \%$ \\
$\begin{array}{l}\text { Symptoms of localization } \\
\text { No symptoms of localization }\end{array}$ & $68 \%$ & $71 \%$ & $100 \%$ \\
$\begin{array}{l}\text { Fits of epilepsy or tonic fits } \\
\text { of posterior fossa }\end{array}$ & $85 \%$ & $12 \%$ & - \\
\hline
\end{tabular}

There are some indications which may be helpful in arriving at a diagnosis of tuberculoma, and they include the patient's history, the clinical examination, and various complementary tests. We are entitled to expect the presence of a tuberculoma when there is a source of tuberculous infection either in the patient himself or in his environment and when there are poor living conditions or debilitating illnesses. Especially is this the case in a young patient in whom a neurological examination reveals intracranial hypertension, with changes in the fundus oculi noted in $94 \%$ of cases, either in the form of active papilloedema $(51 \%)$ or of early secondary optic atrophy $(43 \%)$, with or without signs of localization, and with a slow course and a tendency towards remission. A diagnosis of tuberculoma can sometimes be made without the presence of pulmonary lesions and with a negative history of tuberculosis.

The diagnosis may be further clarified by means of chest radiographs, tuberculin tests (positive in $25 \%$ of tuberculoma cases in children), and simple skull radiographs when calcification will be found in $5.5 \%$ of cases (Figs. 3 and 4). Exceptionally $(1 \%)$ ophthalmoscopic examination may reveal tuberculous lesions. The E.S.R. is less important for it was increased in only $15 \%$ of instances. 

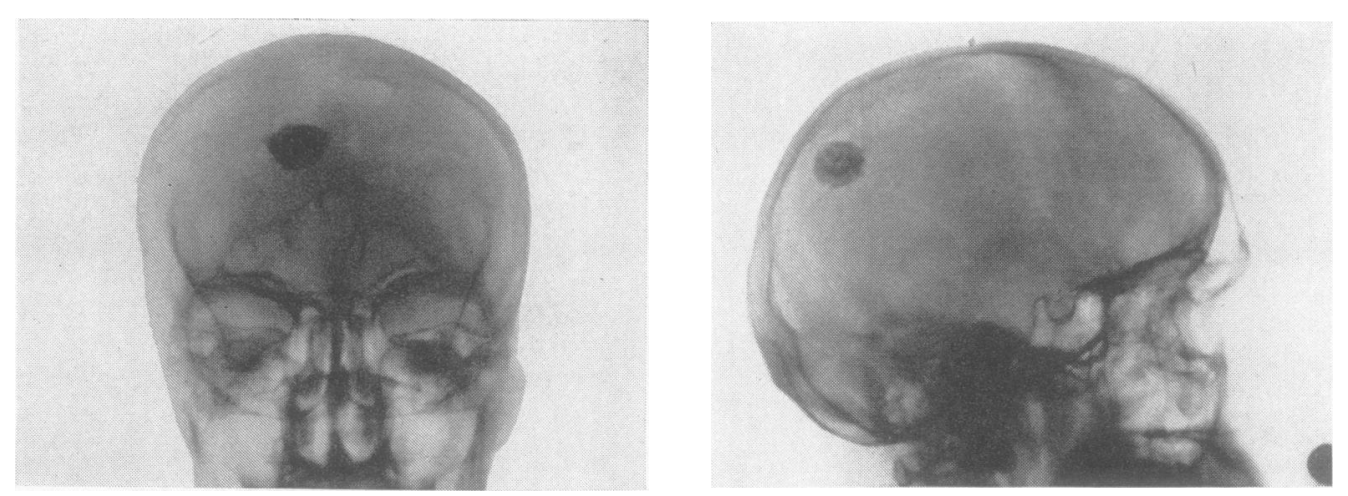

FIGS. 3 and 4.-Frontal and lateral radiographs of skull, showing characteristic tuberculoma calcifications.

Hypochromic anaemia, however, was frequently encountered, with a relatively high lymphocyte count and a lack of eosinophils. Low-grade fever was noted in $10 \%$ of the patients.

Based on a correct interpretation of the personal and family history, as well as on the neurological signs and on the complementary tests, a clinical diagnosis of cerebral tuberculoma could be made in $85 \%$ of the cases subsequently operated on.

A differential diagnosis from other intracranial expanding processes has to be made. It is sometimes difficult in those cases of tuberculoma in which there is no evidence of a previous tuberculous infection either in the patient himself or in his family, and in which the complementary tests are negative. The reverse frequently occurs in those instances of cerebral tumour in patients having recently suffered from listlessness or having a history of tuberculosis. It may be difficult to establish a differential diagnosis from occlusive basal meningitis appearing some three weeks to three months after some debilitating disease. The distinction from medulloblastoma of the posterior fossa is easily made, although both diseases are commonly met with in children with manifest signs of intracranial hypertension. In medulloblastoma marked cerebellar and pyramidal signs are often prominent and progress rapidly, while in tuberculoma focal signs are usually only slight.

The prognosis depends upon: (a) The general condition; $(b)$ the degree and the duration of the intracranial hypertension; $(c)$ the presence of other tuberculous lesions in the body (visceral tuberculosis in association with tuberculoma of the nervous system is of serious import); (d) the site of the tuberculoma and its relation to the dura mater and the circulation of the cerebrospinal fluid; a tuberculoma of the pons may have a fatal outcome, and tuberculomas which adhere to the dura mater or to the ventricular walls are more liable to induce meningitis; (e) the moment of surgical intervention, since an operation at a late stage, when there is severe internal hydrocephalus and cachexia, cannot be expected to yield a good result.

The treatment of brain tuberculoma is both medical and surgical. Before the discovery of streptomycin the excision of the tuberculoma alone or with the surrounding nervous tissue was usually followed by meningitis, so in most cases we were content with simple decompression. Of the $60 \mathbb{D}$ patients operated on before the days of streptomycin, there was a general operative mortality of $10 \%$ and a subsequent mortality from meningitis of $40 \%$. In radical operations, the surgical mortality added to the mortality from meningitis was as high as $84.5 \%$. All cases of tuberculoma excised from the posterior fossa succumbed through menginitis, while six out of eight cases of excision of supratentorial tuberculoma had a fatal outcome. In palliative operations, without excision of the tuberculoma, there was a mortality of $9 \%$ through operation and of $28 \%$ through meningitis, with a survival rate of $66 \%$. By decompression and leaving the tuberculoma untouched survival times lasting up to 19 years were obtained (Table IV).

We have operated on and treated with streptomycin 141 cases of supra- or infra-tentorial tuberculoma, with a surgical mortality of $6.3 \%$, a mortality from post-operative meningitis of $6 \%$, and mortality from operation plus meningitis of $12 \%$. Complete recovery was obtained in $88 \%$ of the cases (Table V).

Surgical mortality was high in tuberculoma of the brain-stem and of the basal ganglia, as well as in cases with hydrocephalus and cachexia. However, six out of eight patients with tuberculoma of the basal ganglia have been operated on, and four of them are alive. Details of these cases may be found in a paper published elsewhere. 
TABLE IV

DELAYED RESULTS RELATED TO THE SURGICAL PROCEDURE EMPLOYED IN 60 CASES OF TUBERCULOMA OPERATED BEFORE THE USE OF STREPTOMYCIN

\begin{tabular}{|c|c|c|c|c|c|}
\hline \multirow[b]{2}{*}{$\begin{array}{c}\text { Surgical } \\
\text { Procedure }\end{array}$} & \multirow[b]{2}{*}{ Site } & \multicolumn{3}{|c|}{ Results } & \multirow{2}{*}{$\begin{array}{l}\text { Percentage } \\
\text { of Surgical } \\
\text { plus } \\
\text { Meningitis } \\
\text { Mortality }\end{array}$} \\
\hline & & Alive & $\begin{array}{l}\text { Surgical } \\
\text { Mor- } \\
\text { tality }\end{array}$ & $\begin{array}{c}\text { Menin- } \\
\text { gitis } \\
\text { Mortality }\end{array}$ & \\
\hline \multirow[t]{2}{*}{$\begin{array}{l}\text { Palliative (de- } \\
\text { compression) } \\
\text { (47 cases) }\end{array}$} & $\begin{array}{l}\text { Infraten- } \\
\text { torial } \\
\text { (38 cases) }\end{array}$ & $26(70 \%)$ & $3(8 \%)$ & $9(26 \%)$ & \multirow{2}{*}{34} \\
\hline & $\begin{array}{l}\text { Supra- } \\
\text { tentorial } \\
(9 \text { cases) }\end{array}$ & $5(55 \%)$ & $1(11 \%)$ & $3(37.5 \%)$ & \\
\hline \multirow[t]{2}{*}{$\begin{array}{l}\text { Radical } \\
\text { (excision) } \\
\text { (13 cases) }\end{array}$} & $\begin{array}{l}\text { Infraten- } \\
\text { torial } \\
\text { (4 cases) }\end{array}$ & - & $1(25 \%)$ & $3(100 \%)$ & \multirow{2}{*}{$84 \cdot 5$} \\
\hline & $\begin{array}{l}\text { Supra- } \\
\text { tentorial } \\
(9 \text { cases) }\end{array}$ & $2(22 \%)$ & $1(11 \%)$ & $6(75 \%)$ & \\
\hline Total 60 cases & & & $6(10 \%)$ & $21(40 \%)$ & \\
\hline
\end{tabular}

Mortality from meningitis was early in six cases and it was due to insufficient treatment in one case; to active visceral tuberculosis in three cases; and to multiple brain tuberculomas, causing repeated attacks of meningitis in two; in another two instances meningitis appeared late, three to six
TABLE V

DELAYED RESULTS IN 141 CASES OF TUBERCULOMA OPERATED ON AND TREATED WITH STREPTOMYCIN

\begin{tabular}{|c|c|c|c|}
\hline \multirow[b]{2}{*}{ Surgical Procedure } & \multicolumn{3}{|c|}{ Results } \\
\hline & Alive & $\begin{array}{c}\text { Surgical } \\
\text { Mortality }\end{array}$ & $\begin{array}{l}\text { Meningitis } \\
\text { Mortality }\end{array}$ \\
\hline $\begin{array}{l}\text { Palliative (decompression) in } \\
\text { brain-stem tuberculomas in } \\
6 \text { cases } \\
\text { Radical (excision) infraten- } \\
\text { torial in } 86 \text { cases } \\
\text { Radical (excision) supra- } \\
\text { tentorial in } 49 \text { cases }\end{array}$ & $\begin{array}{c}2(33 \%) \\
76 \\
46\end{array}$ & $\begin{array}{c}2(33 \%) \\
5 \\
2\end{array}$ & $\begin{array}{c}2(50 \%) \\
5 \\
1\end{array}$ \\
\hline Total: 141 cases & $124(88 \%)$ & $9(6.3 \%)$ & $8(6 \%)$ \\
\hline
\end{tabular}

months after the operation, in spite of intensive postoperative treatment.

In the last 71 patients we had two post-operative casualties and no case of meningitis. All cases (12) of multiple (two to six) cerebellar tuberculoma recovered.

Streptomycin was used by the intramuscular route only in daily doses of $1 \mathrm{~g}$. at a time, up to $80 \mathrm{~g}$., from the time that the temperature and the cerebrospinal fluid became normal. Lately, we have added I.N.A.H. in doses of $10 \mathrm{mg}$. per $\mathrm{kg}$. body weight.

\section{THE AUGUST (1958) ISSUE}

The August (1958) issue contains the following papers:-

Cerebellar Hypoplasia Associated with Systemic Degeneration in Early Life. R. M. Norman and H. Urich. Clinical and Electroencephalographic Observations in Alzheimer's Disease. F. Letemendia and G. Pampiglione. Investigations of E.E.G. Findings in Presenile Dementia. D. W. Liddell.

The Centrifugal Pathway for Micturition within the Spinal Cord. P. W. Nathan and Marion C. Smith.

Language Disorder in a Case of Korsakoff's Syndrome. P. R. F. Clarke, Maria Wyke, and O. L. Zangwill.

The Surgical Separation of Siamese Twins Conjoined by the Heads (Cephalopagus Frontalis) Followed by Normal Development. Maitland Baldwin and Anatole Dekaban.

Yawning. Jacques Barbizet.

Ophthalmic Herpes Zoster with Contralateral Hemiplegia. C. Anastasopoulos, K. Routsonis, and C. S. Ierodiakonou. A Preliminary Report on the Lack of Toxicity of a Preparation of Total Rauwolfia Alkaloids. Homai M. Colabawalla. The Syndrome of Acute Central Cervical Spinal Cord Injury. Richard C. Schneider, John M. Thompson, and Jose Bebin.

Proceedings of the Society of British Neurological Surgeons: 57th Meeting.

Book Reviews.

A number of copies are still available and may be obtained from the Publishing Manager, British Medical Association, Tavistock Square, W.C.1, price 17s. $6 d$. 